\title{
Screening for Diabetes Associated Glucosuria in Urine of Rural Dwellers of Uwokwu District Of Oju Local Government Area of Benue State.
}

\author{
Duru $\mathrm{BN}^{1 *}$., Kinjir $\mathrm{HJ}^{2}$., Yakunat $\mathrm{OE}^{2}$., Abilu $\mathrm{CA}^{2}$., Mohammed $\mathrm{SJ}^{2}$., Nimbut \\ $\mathrm{LB}^{2}$., Duile $\mathrm{PT}^{3}$., Adeyanju $\mathrm{ON}^{3}$., Gambo $\mathrm{PP}^{3}$., Fwogos $\mathrm{IC}^{3}$., Mukaila $\mathrm{FB}^{3}$., \\ Lokason $\mathrm{SD}^{4}$., Ibrahim $\mathrm{L}^{4}$., Peter $\mathrm{L}^{4}$., Okafor $\mathrm{NC}^{4}$., Tyem $\mathrm{DA}^{4}$. \\ ${ }^{1}$ (Dept of Chemical Path.FCVMLT/Side Lab. FCAHPT /Diagnostic/Parasitology, NVRI,Vom) \\ ${ }^{2}$ (Div Bact. Vacc. Prod./Histology/Histology/Hematology/Chempath,FCVMLT/NVRI,Vom) \\ ${ }^{3}$ (Dept of Chemical Path CHT, Pankshin/Zawan\&Vir./Bact.Vacc.Prod./Diagnostic//NVRI,Vom) \\ ${ }^{4}$ (Central Diagnostic Div/Livestock Investigation/Applied Biotechnology, NVRI,Vom) \\ Corresponding Author: Duru Boniface Nnamdi, email: aefuleforu@ymail.com Phone: +2348035873744. \\ Department of Chemical Pathology, F C V M L T, PMB 02, Vom. Postcode $=930010$. Nigeria.
}

\begin{abstract}
A public screening of diabetes associated glucosuria in urine was the focus of this study. The population was randomly selected from five different communities namely Igwe Ebong, Ebenta, Ochekpo, Igwe Oke, and Ikwoku communities of Uwokwu district of Oju Local government area. A total of 800 people age between 10 and 75 years were screened. 406 were males and 394 were females. Random urine glucose analysis (urinalysis) was by use of qualitative visual reading technique to detect urine glucose. Glucosuria was detected in urine of two subjects between ages 41 and 50 among the males, the age known for adult on set of type 2 diabetes representing $0.49 \%$ of the total males while none were found in the females. This presumed undiagnosed diabetes found in the two subjects of the study population may be an indication of a gradual emergence of the disease. It was concluded from this study that there was a low prevalence of diabetes associated glucosuria $0.25 \%$ of the total population making up the communities with a need for people of the area to undergo regular screening of their urine as a preventive and early diagnosis of diabetes and other associated diseases.
\end{abstract}

\section{Introduction}

Diabetes mellitus also known simply as diabetes is a group of metabolic disorder of carbohydrate metabolism in which glucose is underutilized producing hyperglycemia over a long period [1]. It is characterized by high blood glucose either because the body does not produce enough insulin or because cells do not respond to the insulin that is produced [2]. Diabetes is one of the first diseases described [3] with an Egyptian manuscript from c. 1500 BCE mentioning "too great emptying of the urine [4].

Some causes of diabetes mellitus includes; Insufficient insulin production and utilization, Fibrocystic disease of the pancreas, Destruction of pancreatic islets of langerhans figure 1, Infant with low birth weight has a high potential of developing type 2 diabetes later in life [5], age older than 45 years, obesity weight greater than $120 \%$ of desirable body weight (true for $90 \%$ of patients with type 2 diabetes mellitus), history of impaired glucose tolerance (IGT) or impaired fasting glucose level (IFG), hypertension, blood pressure greater than $140 / 90 \mathrm{~mm} / \mathrm{Hg}$ or hyperlipidemia (high density lipoprotein (HDL) cholesterol less than $35 \mathrm{mg} / \mathrm{L}$ or triglyceride level greater than $250 \mathrm{mg} / \mathrm{L}$, history of gestational diabetes or delivering a baby with body weight more than $5 \mathrm{~kg}$ [6].

Untreated, diabetes can cause many complications[7]. Acute complications include diabetic ketoacidosis and nonketotic hyperosmolar coma[8]. Serious long-term complications include heart disease, stroke, kidney failure, foot ulcers figure 2 and damage to the eyes [7].

The classic symptoms of untreated diabetes are weight loss, polyuria (frequent urination), polydipsia (increased thirst), and polyphagia (increased hunger)[9]. which are known to show rapidly in a type1while developing much more slowly and even subtly or absent in type 2 diabetes figure 3 .

Several other signs and symptoms can mark the onset of diabetes, although they are not specific to the disease. In addition to the well known ones above, they include blurry vision, headache, fatigue, slow healing of cuts, and itchy skin. Prolonged high blood glucose can cause glucose absorption in the lens of the eye, which leads to changes in its shape, resulting in vision changes [9] figure 4.

There are three main types of diabetes mellitus namely type 1 diabetes mellitus said to result from the body's failure to produce enough insulin and previously referred to as "insulin-dependent diabetes mellitus" 
(IDDM) or "juvenile diabetes " of which the cause is unknown3. Type 2 diabetes mellitus begins with insulin resistance, a condition in which cells fail to respond to insulin properly [7]. As the disease progresses a lack of insulin may also develop [[10]. This form was previously referred to as non insulin-dependent diabetes mellitus (NIDDM) or "adult-onset diabetes". The primary cause is excessive body weight and not enough exercise3. Gestational diabetes is the third main form and occurs when pregnant women without a previous history of diabetes develop a high blood glucose level [7].

Diabetes can be screened by urine analysis. Although urine analysis may be used to detect glucose, a urine test alone does not diagnosed diabetes. A follow up of blood tests must be carried out to confirm it [11]. Nevertheless, the use of a urine analysis to detect the presence of glucose in a urine sample can help in arresting the condition on time.

Globally, as of 2013, an estimated 382 million people have diabetes worldwide, with type 2 diabetes making up about $90 \%$ of the cases [12][13]. This is equal to $8.3 \%$ of the adult's population [13], with equal rates in both women and men [14]. Worldwide in 2012 and 2013 diabetes resulted in 1.5 to 5.1 million deaths per year, making it the 8th leading cause of death[15][16]. Diabetes overall at least doubles the risk of death [7]. The number of people with diabetes is expected to rise to 592 million by 2035[17]. The economic costs of diabetes globally was estimated in 2013 at $\$ 548$ billion[16] and in the United States in 2012 \$245 billion[18].

Diabetes is a growing problem in the developing Countries including Nigeria and according to a national survey in 1992 which estimated the prevalence of the disorder at 1.6\%[19]. Most cases of Diabetes in developing countries remain undiagnosed, because many of the symptoms seem so harmless. Recent studies indicate that the early detection of diabetes symptoms and treatment can decrease the chances of developing the complication [20].

\subsection{Justification}

Diabetes is a growing problem in the developing countries including Nigeria. Most cases of diabetes in Nigeria remain undiagnosed because many of the symptoms seem so harmless and most people especially in the rural areas are still ignorant of the disease. Early detection of diabetes mellitus and its treatment can decrease the chances of developing the complications.

\subsection{Aims And Objectives}

1. To detect the presence of glucose in the urine of the study population.

2. To assess the prevalence of diabetes associated glucosuria among the population

\subsection{Reagent For Detection Of Glucose In Urine}

\section{Materials And Methods}

The clinical reagents used in this study were procured from TECO Diagnostics Products.

\subsection{Subjects Selection}

Subjects for this study were randomly selected from schools, offices and public places in five different communities in Uwokwu District of Oju L.G.A. These communities includes: Igwe Ebong, Oche-ekpo, Ebenta, Igwe-oke and Ikwokwu. The respondents were ages between 10 to 70 years. There were 800 respondents out of which 406 males and 394 females.

\subsection{Administration Of Questionnaire}

Questionnaires were distributed after informed consent seeking for information to include and exclude subjects in the study. Among the inclusion criteria were; those who were not diabetic, those who were not pregnant, and those who are not on drugs or herbs and not suffering from any known disease. While exclusion criteria includes; those who were already diabetic, those who were pregnant, those who were on drugs and herbs especially known to cause hyperglycaemia as well as those suffering any ailment.

\subsection{Sample Collection}

Fresh urine sample were collected into sterile and dry plastic universal bottles

\subsection{Method}

\subsection{1procedure VisualReadingTechnique}

The reagent area of the strip was immersed in the fresh, urjne specimen and taken up -quickly and immediately. The edge of strip was run against the rim of the container to remove the excess urine

The strip was held up horizontally and the result on the strip compared with the color chart on the bottle, notes were made on the results after one minute. 


\section{Results}

Table 1: Shows The Number And Percentage Of Males, Females And \% Distribution Of The Subjects Screened According To Their Age Range.

\begin{tabular}{llllll}
\hline AGE (YEAR) & NO OF & NO OF & TOTAL & \multicolumn{2}{c}{ PERCENTAGE (\%) } \\
& MALES & FEMALES & & MALES & FEMALES \\
\hline $20-20$ & 214 & 155 & 369 & $52.7 \%$ & $39.34 \%$ \\
$21-30$ & 38 & 62 & 100 & $9.36 \%$ & $15.74 \%$ \\
$31-40$ & 46 & 70 & 116 & $11.33 \%$ & $17.77 \%$ \\
$40-50$ & 50 & 39 & 89 & $12.32 \%$ & $9.90 \%$ \\
$51-60$ & 40 & 45 & 85 & $9.85 \%$ & $11.42 \%$ \\
60 and Above & 18 & 23 & 41 & $4.43 \%$ & $5.84 \%$ \\
& & & & & \\
\hline Total & $\mathbf{4 0 6}$ & $\mathbf{3 9 4}$ & $\mathbf{8 0 0}$ & $\mathbf{1 0 0}$ & $\mathbf{1 0 0}$ \\
\hline
\end{tabular}

Table 2: Shows No Of Negative And Positive Semi Qualitative Detection Of Glucos In The Urine Of Male Subjects Screened.

\begin{tabular}{|c|c|c|c|c|c|}
\hline AGE (YEAR) & NO OF MALE & $\begin{array}{l}\text { NO OF } \\
\text { NEGATIVE }\end{array}$ & $\begin{array}{l}\text { NO OF } \\
\text { POSITIVE }\end{array}$ & $\begin{array}{l}\text { PERCENTAGE } \\
(\%)\end{array}$ & NEGATIVE \\
\hline $10-20$ & 214 & 214 & NIL & 52.71 & \\
\hline $21-30$ & 38 & 38 & NIL & $9.36 \quad$ NIL & \\
\hline $31-40$ & 46 & 46 & NIL & 11.33 NIL & \\
\hline $41-50$ & 50 & 48 & 2 & $11.82 \quad 0.49 \%$ & \\
\hline $51-60$ & 40 & 40 & NIL & $9.85 \quad$ NIL & \\
\hline 60 and Above & 18 & 10 & NIL & 4.43 & \\
\hline Total & 406 & 404 & 2 & 0.49 & \\
\hline
\end{tabular}

Table 3 Shows Number And Percentage Of Negative And Positive Semiqualitative Detection Of Glucose In The Urine Of Female Subjects Screened

\begin{tabular}{lllll}
\hline Age (Year) & No Of Female & NoOf Negative & $\begin{array}{l}\text { No Of } \\
\text { Positive }\end{array}$ & $\begin{array}{l}\text { Percentage } \\
\text { Negative (\%) }\end{array}$ \\
\hline & & & & \\
$10-20$ & 155 & 155 & NIL & 39.34 \\
$21-30$ & 62 & 62 & NIL & 15.74 \\
$31-40$ & 70 & 70 & NIL & 17.77 \\
$41-50$ & 39 & 39 & NIL & 9.90 \\
$51-60$ & 45 & 45 & NIL & 11.42 \\
60 and Above & 23 & 23 & NIL & 5.84 \\
\hline & & & & \\
Total & $\mathbf{3 9 4}$ & $\mathbf{3 9 4}$ & & $\mathbf{1 0 0}$ \\
\hline
\end{tabular}

Table 4 Shows Occupational Distribution and Percentage (\%) Of The Various Age Groups Based On Their Sex.

\begin{tabular}{|c|c|c|c|c|}
\hline \multirow[b]{2}{*}{ OCCUPATION } & \multicolumn{2}{|c|}{ SEX } & \multirow[b]{2}{*}{ TOTAL } & \multirow[b]{2}{*}{$\%$} \\
\hline & MALE & FEMALE & & \\
\hline Civil servants & 35 & 6 & 41 & 5.13 \\
\hline Students & 242 & 177 & 419 & 52.38 \\
\hline Farmers & 200 & 140 & 340 & 42.50 \\
\hline Total & 477 & 323 & 800 & 100 \\
\hline
\end{tabular}

\section{Dicussion}

The subjects were selected randomly from primary schools, secondary schools, peasant farmers and civil servants of ages range 10-70years. From the results obtained in table 1, a total of 214 males were found to be between the ages of $10-20$ year, which is higher than the number of females 155 within the same age range. This difference between the number of males and females within this age range may be due to the fact that more males are sent to school compared to females in the study communities. However females appear to be more than males across all the other age ranges table1. From the questionnaire, it may be either due to the fact that 
most men in this environment especially between the ages of 21 and 55 years go to the cities in search of greener pastures.

Table 2, shows that 404 males out of total of 406 males screened appeared to be negative for glucose in their urine implying the absence of diabetes. However two males out of the total number screened showed positive for glucose test in their urine and therefore presumed to be having diabetes. Although the presence of glucose in the urine is known as glycosuria or glucosuria [11]. According to report by [21] urine usually contains no glucose because the kidneys are able to reclaim all of the filtered glucose back into the bloodstream, however glycosuria is nearly always caused by elevated blood glucose levels, most commonly due to untreated diabetes mellitus which may be the case for the two positive subjects. This is further confirmed from the questionnaire in which they affirmed no knowledge of suffering from any disease. In many literatures on diabetes and particularly type 2 said to be the adult on set, symptoms may often times not be experienced by the patient(s)[22][23][24].It was also worthy of note that the two positive subjects both fell within the same age range of 41-50years. Several reports abound that increasing age is known to be a risk factor for the development of type 2 diabetes mellitus [23] and people from 45 and above should regularly screen their glucose level [22]. In addition also from the questionnaires the two subjects were shown to have most of the symptoms associated with the disease such as, polyuria, polyphagia, Blurred vision, Numbness in hands and feet, very dry skin, polydipsia (increase thirst) [22][23]. Another factor is the dietary life style in this community which is largely carbohydrates. Prevention and treatment involves a healthy diet, physical exercise, not using tobacco, and being a normal body weight. Blood pressure control and proper foot care are also important for people with the disease.[7].The two positive subjects were asked to go for further laboratory analysis in a well recognized standard hospital in the Local Government headquarter

The results obtained in Table 3 shows that all the females subjects screened appeared to be $100 \%$ negative for glucose in their urine. This could be due to the fact that the women are hard working as most of them combine farm work, business and domestic activities as observed from the questionnaires. These activities help them to burn excessive fats, thereby maintaining desirable body weight[6]. Prevention and treatment involves a healthy diet, physical exercise, not using tabacco, and being a normal body weight. Blood pressure control and proper foot care are also important for people with the disease.[7]. It is also stated that exercise are recommended in attempt to induce weight loss and to reverse the insulin resistance in persons with type 2 diabetes[24][25].

Although as can be seen in table 4 and from the questionnaires as well that, the two positive subjects were civil servants but were not going for any regular checkup, in addition to living a sedentary life style which is an important risk factor for developing diabetes. The development of type 2 diabetes is caused by a combination of lifestyle and genetic factors[26][27]. While some of these factors are under personal control, such as diet and obesity, other factors are not, such as increasing age, female gender, and genetics[28]. Another factor is the dietary life style in this community which is largely carbohydrates. Dietary factors also influence the risk of developing type 2 diabetes. Consumption of sugar-sweetened drinks in excess is associated with an increased risk[29][30]. The type of fats in the diet are also important, with saturated fat and transfatty acid increasing the risk, and polyunsaturated and monounsaturated decreasing the risk[27]. Eating lots of white rice appears to also play a role in increasing risk.[31]. A lack of exercise is believed to cause $7 \%$ of cases[32].

It is also observed in this study that no single case of glucosuria in urine was found among the farming groups irrespective of their ages and dietary life style. This could be as a result of exercise they do as their profession involves a lot of strenuous activities. This justifies the statement above that sedentary life style is an important risk factor for diabetes A number of lifestyle factors are known to be important to the development of type 2 diabetes, including obesity and overweight (defined by a body mass index of greater than 25), lack of physical activity, poor diet, stress, and urbanization [33][34].

This study also showed from the questionnaire that about $90 \%$ of these people have never gone for common urine analysis not to mention other relevant medical examinations. Report in the literatures have indicated that rates of undiagnosed diabetes population could be as high as $45-60 \%$ [35][36].

\section{Conclusion}

It can be concluded from this study that there were low prevalence of diabetes mellitus in Igwe Ebong, Ebenta, Ochekpo, Igwe oke and Ikwokwo communities based on urine glucose dip strip test. Individuals found positive to urine glucose dip strip test were asked to go for further laboratory investigation for confirmation of diabetes mellitus.

\section{Recommendation}

Diabetes awareness program be promoted with a view to identify people with diabetes early enough so that appropriate treatment and management could be instituted. 


\section{References}

[1]. About diabetes". World Health Organization. Retrieved 4 April 2014

[2]. http://diabetesmelitusdisorder.blogspot.com/2010/10/what-is-diabetes-melitus.html

[3]. Ripoll, Brian C. Leutholtz, Ignacio. Exercise and disease management (2nd ed.). Boca Raton: CRC Press. p. 25. ISBN 978-1-43982759-8.

[4]. Leonid Poretsky, (2009). Principles of diabetes mellitus (2nd ed.). New York: Springer. p. 3. ISBN 978-0-387-09840-1.

[5]. Joslin Diabetes Centre (2005). Release article Nutritional Guidelines for People with type 2 Diabetes or Pre-diabetes who are overweight or bese.www.joslin.org/info/diet_and_diabetes_a_personalized_approach.html

[6]. American Diabetes Association; Release article title all about diabetes, (2004).

[7]. "Diabetes Fact sheet N³12". WHO. October 2013. Retrieved 25 March 2014.

[8]. Ripsin CM, Kang H, Urban RJ (January 2009). "Management of blood glucose in type 2 diabetes mellitus". Am Fam Physician 79 (1): 29-36. PMID 19145963.

[9]. Lee, I-Min; Shiroma, Eric J; Lobelo, Felipe; Puska, Pekka; Blair, Steven N; Katzmarzyk, Peter T (1 July 2012). "Effect of physical inactivity on major non-communicable diseases worldwide: an analysis of burden of disease and life expectancy". The Lancet 380 (9838): 219-29. doi:10.1016/S0140-6736(12)61031-9. PMC 3645500. PMID 22818936.

[10]. RSSDI textbook of diabetes mellitus. (Rev. 2nd ed. ed.). New Delhi: Jaypee Brothers Medical Publishers. 2012. p. 235. ISBN 9789350254899

[11]. McPherson RA, Ben-Ezra J. Basic examination of urine. In: McPherson RA, Pincus MR, eds. Henry's Clinical Diagnosis and Management by Laboratory Methods. 22nd ed. Philadelphia, Pa: Elsevier Saunders; 2011:chap 28.

[12]. Williams textbook of endocrinology (12th ed.). Philadelphia: Elsevier/Saunders. pp. 1371-1435. ISBN 978-1-4377-0324-5. 11

[13]. Shi, Yuankai; Hu, Frank B. "The global implications of diabetes and cancer". The Lancet 383 (9933): $1947-1948$. doi:10.1016/S0140-6736(14)60886-2. 12

[14]. Vos T, Flaxman AD, Naghavi M, Lozano R, Michaud C, Ezzati M, Shibuya K, Salomon JA, Abdalla S, Aboyans V, et al. (Dec 15, 2012). "Years lived with disability (YLDs) for 1160 sequelae of 289 diseases and injuries 1990-2010: a systematic analysis for the Global Burden of Disease Study 2010.". Lancet 380 (9859): 2163-96. PMID 23245607.13

[15]. "The top 10 causes of death Fact sheet N³10". World Health Organization. Oct 2013.14

[16]. IDF DIABETES ATLAS (6 ed.). International Diabetes Federation. 2013. p. 7. ISBN 2930229853.15

[17]. "International Diabetes Federation: Diabetes Atlas". Retrieved 4 April 2014.

[18]. American Diabetes, Association (Apr 2013). "Economic costs of diabetes in the U.S. in 2012.". Diabetes care 36 (4): $1033-46$. PMID 23468086.16

[19]. Bakeri A.G, Onyemelukwe G.C, Sani B.G, Hassan S.S, Aliyu T.M (1999) Prevalence of diabetes mellitus in sub-urban Northern Nigeria. Result of Public Screening Survey.Diabetes International. 9:59-60.

[20]. King H, Auberi R.E Herman (1998). Who Global Burded of Diabetes 1995-2025 Prevalence, Numerical Estimates and Projection Diabetes Care, 21, 1414-1431.

[21]. Rose, Burton; Rennke, Helmut (1994). Renal pathophysiology - the essentials (1st ed ed.). Philadelphia: Lippincott Williams \& Wilkins. p. 194. ISBN 0-683-07354-0.

[22]. American Diabetes Association. Standards of medical care in diabetes -- 2013. Diabetes Care. 2013; Jan;33 Suppl 1:S11-S61.

[23]. Alemzadeh R, Ali O. Diabetes mellitus. In: Kliegman RM, ed. Kliegman: Nelson Textbook of Pediatrics. 19th ed. Philadelphia, Pa.: Elsevier Saunders; 2011:chap 583.

[24]. Cooke DW, Plotnick L (November 2008). "Type 1 diabetes mellitus in pediatrics". Pediatr Rev 29 (11): $374-84$; quiz 385. doi:10.1542/pir.29-11-374. PMID 18977856.

[25]. Stampfer MJ, Hu FB, Manson JE, Rimm EB, Willett WC (2000). "Primary Prevention of Coronary Heart Disease in Women through Diet and Lifestyle". New England Journal of Medicine 343 (1): 16-22. doi:10.1056/NEJM200007063430103. PMID 10882764.

[26]. Hu FB, Manson JE, Stampfer MJ, Colditz G, Liu S, Solomon CG, Willett WC (2001). "Diet, lifestyle, and the risk of type 2 diabetes mellitus in women". The New England Journal of Medicine 345 (11): 790-797. doi:10.1056/NEJMoa010492. PMID 11556298.

[27]. Ripsin CM, Kang H, Urban RJ (January 2009). "Management of blood glucose in type 2 diabetes mellitus". Am Fam Physician 79 (1): 29-36. PMID 19145963.

[28]. Risérus U, Willett WC, Hu FB (January 2009). "Dietary fats and prevention of type 2 diabetes". Progress in Lipid Research 48 (1): 44-51. doi:10.1016/j.plipres.2008.10.002. PMC 2654180. PMID 19032965.

[29]. Williams textbook of endocrinology. (12th ed.). Philadelphia: Elsevier/Saunders. pp. 1371-1435. ISBN 978-1-4377-0324-5.

[30]. Malik, VS; Popkin, BM, Bray, GA, Després, JP, Hu, FB (2010-03-23). "Sugar Sweetened Beverages, Obesity, Type 2 Diabetes and Cardiovascular Disease risk". Circulation 121 (11): 1356-64. doi:10.1161/CIRCULATIONAHA.109.876185. PMC 2862465. PMID 20308626.

[31]. Malik, VS; Popkin, BM, Bray, GA, Després, JP, Willett, WC, Hu, FB (November 2010). "Sugar-Sweetened Beverages and Risk of Metabolic Syndrome and Type 2 Diabetes: A meta-analysis". Diabetes Care 33 (11): 2477-83. doi:10.2337/dc10-1079. PMC 2963518. PMID 20693348.

[32]. Hu, EA; Pan, A; Malik, V; Sun, Q (2012-03-15). "White rice consumption and risk of type 2 diabetes: meta-analysis and systematic review". BMJ (Clinical research ed.) 344: e1454. doi:10.1136/bmj.e1454. PMC 3307808. PMID 22422870.

[33]. Lee, I-Min; Shiroma, Eric J; Lobelo, Felipe; Puska, Pekka; Blair, Steven N; Katzmarzyk, Peter T (1 July 2012). "Effect of physical inactivity on major non-communicable diseases worldwide: an analysis of burden of disease and life expectancy". The Lancet 380 (9838): 219-29. doi:10.1016/S0140-6736(12)61031-9. PMC 3645500. PMID 22818936.

[34]. Abdullah, A; Peeters, A; de Courten, M; Stoelwinder, J (September 2010). "The magnitude of association between overweight and obesity and the risk of diabetes: a meta-analysis of prospective cohort studies.". Diabetes research and clinical practice 89 (3): $309-$ 19. doi:10.1016/j.diabres.2010.04.012. PMID 20493574.

[35]. WHO (2004). Report and Consultations on definition, diagnosis and classification of diabetes mellitus

[36]. WHO (1999). Definitions, Diagnosis and Classification of diabetes mellitus and its complications WHO, Report. 


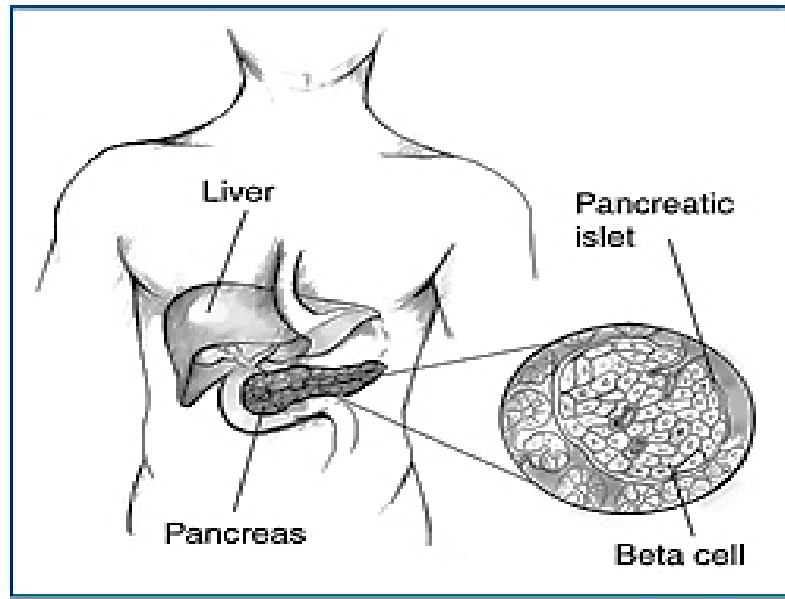

Figure 1 Insulin is made in beta cells in the pancreas. Problems with insulin causes diabetes.

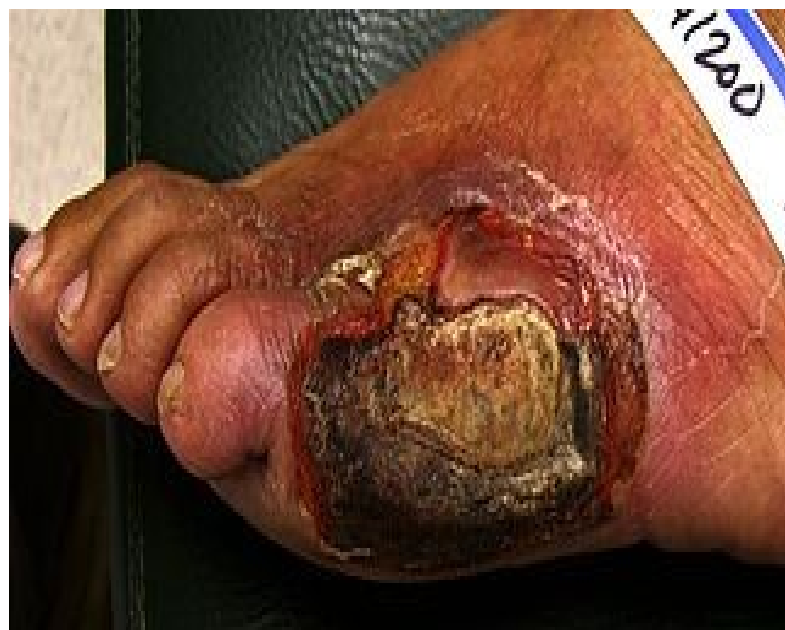

Figure 2 Foot ulcers are a common complication of diabetes and can lead to amputation. This ulcer is further complicated by both wet and dry gangrene.

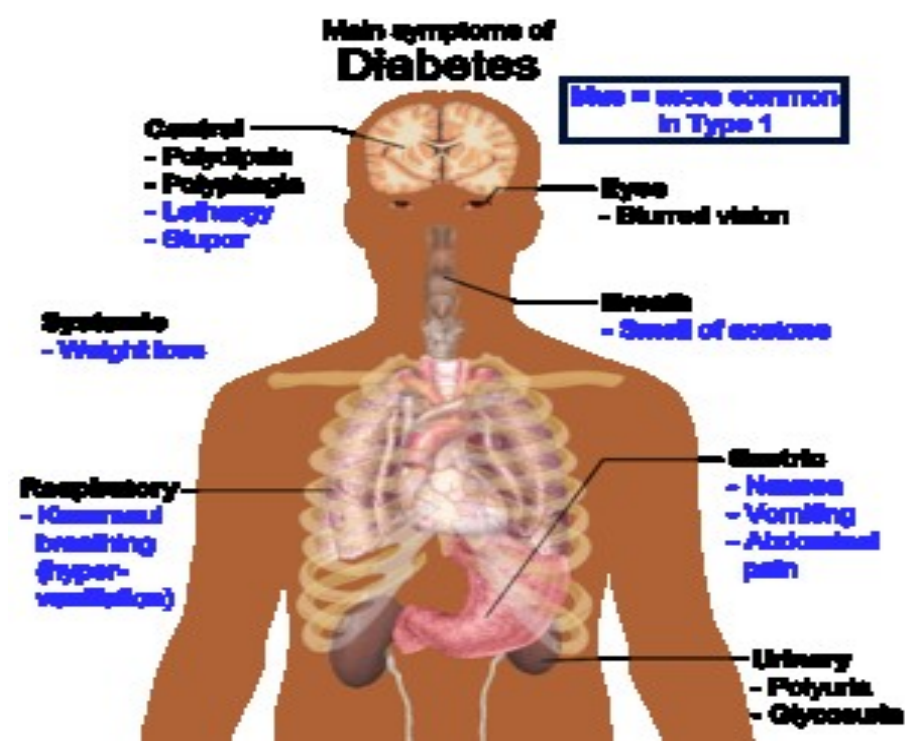

Figure 3 Overview of the most significant symptoms of diabetes 


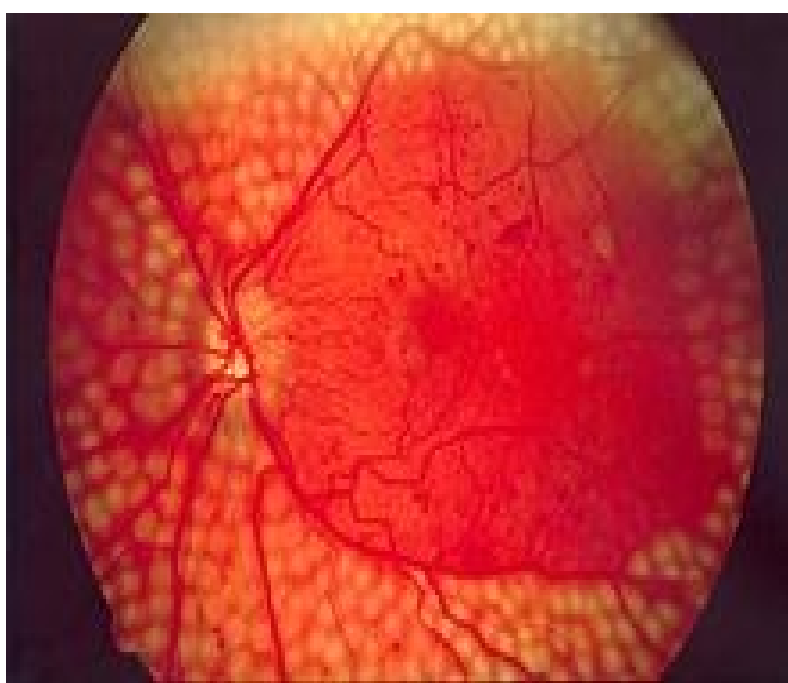

Figure 4 Image of fundus showing scatter laser surgery for diabetic retinopathy 